\title{
Tobacco smoking and the risk of non-melanoma skin cancer
}

Eduardo De Stefani, José Espasandin, Alvaro Ronco, Maria Mendilaharsu, Luis Fierro, Julio Balbi, Maria T Larrinaga

\begin{abstract}
Objective-To examine the association between non-melanoma skin cancer and cigarette smoking.

Design-Hospital-based case-control study covering the period 1988-93.

Subjects - A total of 132 patients ( 73 with basal cell carcinoma and 59 with squamous cell carcinoma), and 395 agefrequency matched controls with diseases unrelated to tobacco use.

Main outcome measures-Odds ratios (ORs) for non-melanoma skin cancer, according to smoking status, after controlling for age, residence, education, and occupational sun exposure through unconditional logistic regression.
\end{abstract}

Results-The OR was significantly higher in current cigarette smokers relative to never-smokers $(O R=2.1,95 \%$ confidence interval $(\mathrm{CI})=1.1$ to 3.9$)$. A significant dose-response relation was observed for smoking duration ( $p$ for trend $=0.002$ ). The $O R$ for ever-smokers of long duration (50 years or more) was $2.3(95 \% \mathrm{CI}=1.2$ to 4.5$)$. Higher risks were observed among current smokers (compared with former smokers) and among patients with squamous cell carcinoma (compared with those with basal cell carcinoma).

Conclusions - Although bias cannot be excluded completely, the positive association between cigarette smoking and nonmelanoma skin cancer in our study supports the evidence from previous studies of a relationship between tobacco smoking and skin cancer. If these findings are replicated in population-based studies, estimates of the number of tobacco-related cancers would be enlarged.

(Tobacco Control 1995; 4: 175-179)

Keywords: cancer, skin; risk; tobacco-associated

\section{Introduction}

The study of risk factors for non-melanoma skin cancer has been mainly related to sun exposure, both occupational and recreational. ${ }^{1,2}$ The role of certain occupations in skin carcinogenesis has been consistently reproduced since the classic paper by Sir Percival
Pott. $^{3}$ In 1985, Aubry and MacGibbon reported an increased risk of squamous cell carcinoma of the skin associated with tobacco consumption. ${ }^{4}$ This association was replicated by Karagas et al, who found an odds ratio of 2.0 for tobacco smoking; this risk was confined to the squamous cell type, whereas smokers were not shown to have an increased risk of basal cell carcinoma. ${ }^{5}$

Given the importance of this issue in elucidating the aetiology of non-melanoma skin cancer, we carried out a case-control study to investigate the association between tobacco smoking and skin cancer.

\section{Subjects and methods}

Since January 1988, all patients attending the Instituto Nacional de Oncologia were interviewed shortly after administrative admittance for diagnosis by two trained social workers using a routine questionnaire designed to obtain information on risk factors for cancer. A database was created through this procedure, from which the study subjects were obtained.

\section{CASE SELECTION}

All patients with non-melanoma skin cancer treated in the dermatological outpatient clinic of the Instituto Nacional de Oncologia in the time period 1988-93 were considered eligible for inclusion in the study, provided that: (a) they were diagnosed with squamous cell or basal cell carcinomas (ICD-O $8070 / 3$ or $8090 / 3$ ); (b) they had localised tumours (stage I, T1); (c) they were resident in Uruguay for a period of at least 10 years; (d) they occurred in men, because the prevalence of smoking in women is very low in this particular population (less than 5\%); and (e) they belonged to a population with a monthly income of less than US $\$ 350$; this segment of the Uruguayan population receives free care in hospitals of the Ministry of Public Health (State Hospitals) This particular clinic at the Institute receives patients from low socioeconomic strata, who are treated in the state hospitals in Montevideo, including the Cancer Institute. Public hospitals located in the remaining counties also refer all patients with skin cancer to the state hospitals in Montevideo (Instituto Nacional de Oncologia, Hospital Pasteur, Hospital Maciel, Hospital de Clinicas, Hospital Pereira Rossell), 
because of the lack of specialised outpatient clinics in those centres.

In the study period, 299 patients with skin cancer were treated at the Cancer Institute. Of these, 114 occurred in women and were thus excluded from the study. From the remaining 186 patients with skin tumours, $47(25.3 \%)$ were excluded because of a diagnosis other than squamous or basal cell carcinoma ( 32 malignant melanomas, 10 malignant lymphomas, two adnexal skin carcinomas, two malignant fibrous histiocytomas, and one classic Kaposi sarcoma). Furthermore, six advanced skin carcinomas $(3.2 \%)$ were also excluded, leading to a final total of 132 nonmelanoma skin carcinomas (73 cases of basal cell carcinoma $(55.3 \%)$ and 59 cases of squamous cell carcinoma $(44.7 \%)$.

\section{CONTROL SELECTION}

In the same period, 2375 male patients were treated in the same Institute with conditions other than non-melanoma skin cancer. Eligibility criteria for control selection were: (a) having a disease not related to tobacco smoking according to the admission diagnosis (malignant diseases considered to be tobacco-related were oral, pharyngeal, oesophageal, stomach, anogenital, sinonasal, nasopharyngeal, lung, laryngeal, bladder, and kidney cancers, along with malignant mesothelioma-cardiovascular, respiratory, oesophageal, and gastric nonneoplastic diseases were not considered to be eligible); (b) residency in Uruguay for at least 10 years; (c) being within the age range $30-89$ years; and (d) having no previous diagnosis of skin cancer. Thus 1406 patients $(59.2 \%)$ with tobacco-related cancers, 176 patients $(7.4 \%)$ with tumours of unknown primary site, 118 patients $(5.0 \%)$ with tobacco-related nonneoplastic diseases, 79 patients $(3.3 \%)$ outside the established age range, 43 patients with terminal disease $(3.1 \%)$, and 10 patients $(0.7 \%)$ with previous skin cancer were excluded from the initial list of potential controls, leading to a sample of 543 patients.

From this sample, $395(72.7 \%)$ were classified by age and randomly sampled in decennia (30-39 .. 80-89 years) and then matched by age-frequency to the patients. The control to patient ratio was 3:1 and all were white.

\section{QUESTIONNAIRE AND DEFINITIONS}

The questionnaire included sociodemographic variables, occupation, a complete history of tobacco and alcohol consumption, and a short food-frequency form. In particular, age at smoking initiation, age at smoking cessation, daily cigarette consumption, filter use, type (colour) of tobacco, and duration of use of hand-rolled cigarettes, were recorded. The composite measure "pack-years" was calculated for each patient.

We defined as never-smokers patients who had smoked less than 1000 cigarettes in their lifetime. Former smokers were those who had smoked at least 1000 cigarettes in their lifetime but who had quit smoking at least a year before the interview date. Current smokers were defined as those who had smoked at least 1000 cigarettes in their lifetime and who were either smokers at the time of the interview or who had quit smoking during the 12 months before the interview. Ever-smokers were current plus former smokers.

Cigarettes were classified according to the method of curing, that is, blond (flue-cured) cigarettes or black (air-cured) cigarettes. Cigarettes were also categorised according to whether they were manufactured (commercially made) or hand-rolled.

Filter use was classified as mixed filter use or lifelong filter use. The former corresponds to smokers who had switched from non-filter to filter cigarettes, whereas the latter represents those who only smoked filter cigarettes. Odds ratios presented in the tables for filter cigarettes refer to mixed or lifelong use of filter cigarettes; ORs presented for use of non-filter cigarettes refer to lifelong use of non-filter cigarettes.

We were interested in having a proxy variable to control for sun exposure. Because this information was not specifically recorded in the routine questionnaire, we created a variable to measure lifelong occupational sun exposure. This was done by categorising occupations into agricultural and non-agricultural groupings. Farmers were chosen as the sun-exposed category because these workers are undoubtedly exposed more to the sun, compared with those in other occupations.

\section{STATISTICAL ANALYSIS}

The study was designed to have a power of $90 \%$ for detecting an odds ratio of 2 for current smokers, significant at the $95 \%$ alphalevel (two-sided test), assuming that $40 \%$ of the controls would be current smokers. We computed ORs as estimates of relative risks, and $95 \%$ confidence intervals from unconditional logistic modelling ${ }^{6}$ using GLIM software. ${ }^{7}$ When a factor could be classified into more than two levels, the significance of the linear trend was assessed by the likelihood ratio test on one degree of freedom, after unfactorising the variable. ${ }^{6}$ Furthermore, to control simultaneously for the effects of several covariates, unconditional multiple logistic regression with maximum likelihood fitting was used. ${ }^{6}$ All regression models included terms for age, education, birthplace, county of residence, and occupational sun exposure. Additional adjustments for relevant dietary items were performed, without significant changes in the estimates. Interactions between terms for occupational sun exposure and tobacco variables were tested.

\section{Results}

Of the patients, $85(83.3 \%)$ had tumours in the head and neck area. Table 1 shows the distribution of controls by diagnostic category. Prostate cancer was the most frequent condition $(33.7 \%)$, followed by colorectal cancer $(16.7 \%)$, and malignant lymphoma $(13.0 \%)$. 
Table 1 Distribution of controls by diagnosis

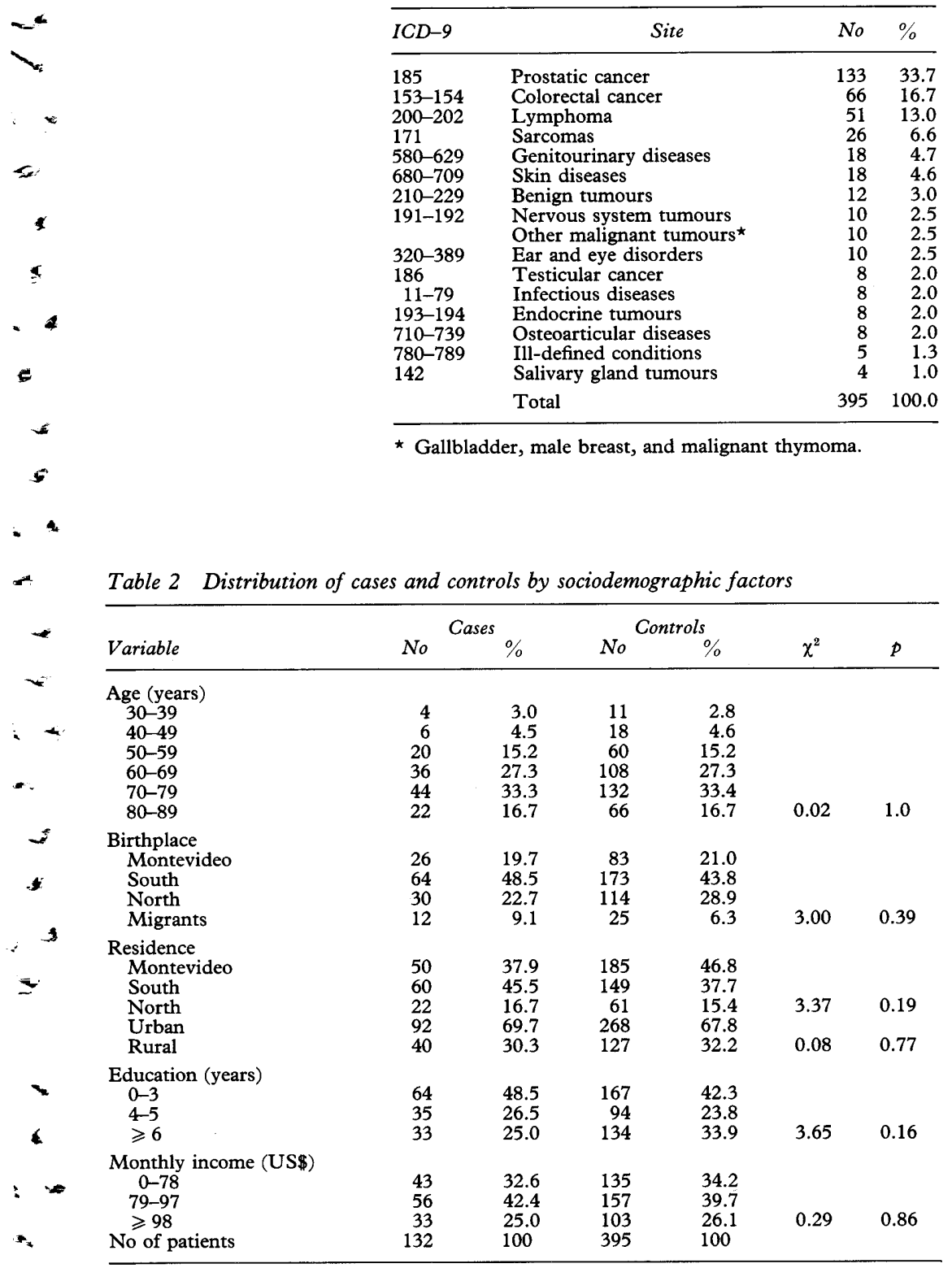

A total of 66 controls (16.7\%) had nonneoplastic diseases.

Table 2 shows the distribution of patients and controls by sociodemographic factors. Patients and controls were similar in terms of age, birthplace, residence, education, and income.

Table 3 shows the ORs for non-melanoma skin cancer (all types) according to several smoking variables. Ever-smokers had a $60 \%$ increased risk of skin cancer. Whereas former smokers had an OR of $1.3(95 \% \mathrm{CI}=0.7$ to 2.3), current smokers displayed a significantly increased risk of 2.1 ( $95 \% \mathrm{CI}=1.1$ to 3.9$)$.

There was no dose-response pattern for daily cigarette consumption. On the other hand, smoking duration showed a significant dose-response pattern, and long duration of smoking (50 or more years) was associated with an OR of $2.3(95 \% \mathrm{CI}=1.2$ to 4.5$)$. The composite measure pack-years showed a pattern of increasing risk, but the test for linear trend was not statistically significant.

The consumption of black tobacco cigarettes was associated with a moderate and significantly increased risk of non-melanoma skin cancer $(\mathrm{OR}=1.8,95 \% \mathrm{CI}=1.0$ to 3.4$)$, compared with never-smokers. The use of hand-rolled cigarettes was associated with a significantly increased risk of similar magnitude. Lifelong use of non-filter cigarettes was associated with an $80 \%$ increased risk of non-melanoma skin cancer.

Table 4 presents ORs of former and current smokers for the same variables. Former smokers showed a modest and non-significant increase in risk (a) overall; (b) with increasing years of smoking and pack-years; (c) with consumption of black tobacco and hand-rolled cigarettes; and (d) with lifelong use of nonfilter cigarettes. On the other hand, current smokers showed significant increased risks with increasing smoking duration and use of hand-rolled and non-filter cigarettes. Con-

Table 3 Odds ratios for non-melanoma skin cancer, by smoking variables ${ }^{\star}$

\begin{tabular}{|c|c|c|c|c|}
\hline Variable & Category & Cases/controls & $O R$ & $95 \% C I$ \\
\hline $\begin{array}{l}\text { Smoking status } \\
\text { Amount (cigarettes/day) }\end{array}$ & $\begin{array}{l}\text { Never-smokers } \\
\text { Ever-smokers } \\
\text { Former smokers } \\
\text { Current smokers } \\
1-12 \\
13-24 \\
\geqslant 25\end{array}$ & $\begin{array}{c}17 / 71 \\
115 / 324 \\
52 / 187 \\
63 / 137 \\
37 / 105 \\
40 / 105 \\
38 / 114\end{array}$ & $\begin{array}{l}1.0 \\
1.6 \\
1.3 \\
2.1 \\
1.6 \\
1.7 \\
1.5\end{array}$ & $\begin{array}{c}\text { NA } \\
0.9-2.8 \\
0.7-2.3 \\
1.1-3.9 \\
0.8-3.1 \\
0.9-3.3 \\
0.8-2.9\end{array}$ \\
\hline Duration (years) & $\begin{array}{l}\quad \chi^{2} \text { for trend }=0.87 \\
1-39 \\
40-49 \\
\geqslant 50\end{array}$ & $\begin{array}{l}37 / 148 \\
25 / 72 \\
53 / 104\end{array}$ & $\begin{array}{l}1.0 \\
1.5 \\
2.3\end{array}$ & $\begin{array}{l}0.5-2.0 \\
0.7-3.1 \\
1.2-4.5\end{array}$ \\
\hline Pack-years & $\begin{array}{l}\chi^{2} \text { for trend }=10.06 \\
1-24 \\
25-54 \\
\geqslant 55\end{array}$ & $\begin{array}{ll}\mathrm{p}=0.002 & \\
& 34 / 114 \\
& 46 / 102 \\
& 35 / 108\end{array}$ & $\begin{array}{l}1.3 \\
2.1 \\
1.4\end{array}$ & $\begin{array}{l}0.7-2.6 \\
1.1-4.1 \\
0.7-2.8\end{array}$ \\
\hline Type of tobacco & $\begin{array}{l}\chi^{2} \text { for trend }=1.79 \\
\text { Blond } \\
\text { Black }\end{array}$ & $\mathrm{p}=0.18$ & $\begin{array}{l}1.2 \\
1.8\end{array}$ & $\begin{array}{l}0.6-2.4 \\
1.0-3.4\end{array}$ \\
\hline Hand-rolling & $\begin{array}{l}\text { Manufactured } \\
\text { Hand-rolled }\end{array}$ & $\begin{array}{l}21 / 90 \\
94 / 234\end{array}$ & $\begin{array}{l}1.1 \\
1.8\end{array}$ & $\begin{array}{l}0.5-2.2 \\
0.9-3.2\end{array}$ \\
\hline Filter use & $\begin{array}{l}\text { Filter } \\
\text { Non-filter }\end{array}$ & $\begin{array}{l}27 / 105 \\
88 / 219\end{array}$ & $\begin{array}{l}1.1 \\
1.8\end{array}$ & $\begin{array}{l}0.6-2.3 \\
0.9-3.2\end{array}$ \\
\hline
\end{tabular}

* All risks are adjusted for age, residence, education, and occupational sun exposure. Odds ratios were calculated for eversmokers (unless otherwise indicated) using never-smokers as the referent group. 
Table 4 Odds ratios for non-melanoma skin cancer stratified by smoking variables ${ }^{\star}$

\begin{tabular}{|c|c|c|c|c|}
\hline \multirow[b]{2}{*}{ Variable } & \multicolumn{2}{|c|}{ Former smokers } & \multicolumn{2}{|c|}{ Current smokers } \\
\hline & $O R$ & $95 \% C I$ & $O R$ & $95 \% C I$ \\
\hline Total & 1.3 & $0.7-2.3$ & 2.1 & $1.1-3.9$ \\
\hline \multicolumn{5}{|c|}{ Amount (cigarettes/day) } \\
\hline $1-12$ & 1.2 & $0.5-2.6$ & 2.1 & $0.9-4.6$ \\
\hline $13-24$ & 1.6 & $0.8-3.5$ & 1.7 & $0.8-3.7$ \\
\hline$\geqslant 25$ & 1.0 & $0.4-2.1$ & 2.2 & $1.0-4.7$ \\
\hline \multicolumn{5}{|l|}{$\begin{array}{l}\text { p Value for trend } \\
\text { Duration (years) }\end{array}$} \\
\hline $1-39$ & 1.0 & $0.5-2.1$ & 1.2 & $0.4-3.3$ \\
\hline $40-49$ & 1.4 & $0.6-3.4$ & 1.3 & $0.5-3.2$ \\
\hline$\geqslant 50$ & 1.6 & $0.7-3.5$ & 2.6 & $1.3-5.2$ \\
\hline \multicolumn{5}{|l|}{$\begin{array}{l}\text { p Value for trend } \\
\text { Pack-years }\end{array}$} \\
\hline $1-24$ & 1.2 & $0.6-2.6$ & 1.4 & $0.6-3.4$ \\
\hline $25-54$ & 1.8 & $0.8-3.8$ & 2.3 & $1.1-4.9$ \\
\hline$\geqslant 55$ & 0.8 & $0.3-1.8$ & 2.1 & $0.9-4.4$ \\
\hline \multicolumn{5}{|l|}{$\begin{array}{l}\text { p Value for trend } \\
\text { Type of tobacco }\end{array}$} \\
\hline $\begin{array}{l}\text { Type of tobacco } \\
\text { Blond }\end{array}$ & & & 1.9 & \\
\hline $\begin{array}{l}\text { Blond } \\
\text { Black }\end{array}$ & $\begin{array}{l}0.7 \\
1.6\end{array}$ & $\begin{array}{l}0.3-1.6 \\
0.8-3.1\end{array}$ & 2.0 & $\begin{array}{l}0.9-4.1 \\
1.0-4.0\end{array}$ \\
\hline \multicolumn{5}{|l|}{ Hand-rolling } \\
\hline Manufactured & 0.9 & $0.4-2.4$ & 1.2 & $0.5-2.8$ \\
\hline Hand-rolled & 1.3 & $0.7-2.5$ & 2.3 & $1.2-4.5$ \\
\hline \multicolumn{5}{|l|}{ Filter use } \\
\hline Filter & 0.9 & $0.4-2.5$ & 1.2 & $0.5-2.7$ \\
\hline Non-filter & 1.3 & $0.7-2.5$ & 2.5 & $1.3-4.9$ \\
\hline
\end{tabular}

* Adjusted for age, residence, education, and occupational sun exposure. Odds ratios were calculated using never-smokers as the referent group.

$\mathrm{CI}=$ confidence interval.

Table 5 Odds ratios for non-melanoma skin cancer, stratified by histologic type ${ }^{\star}$

\begin{tabular}{|c|c|c|c|c|}
\hline \multirow[b]{2}{*}{ Variable } & \multicolumn{2}{|c|}{ Squamous cell } & \multicolumn{2}{|c|}{ Basal cell } \\
\hline & $O R$ & $95 \% C I$ & $O R$ & $95 \% C I$ \\
\hline Never-smokers & 1.0 & NA & 1.0 & NA \\
\hline Ever-smokers & 1.9 & $0.8-4.3$ & 1.5 & $0.7-3.1$ \\
\hline Ex-smokers & 1.4 & $0.6-3.5$ & 1.2 & $0.6-2.6$ \\
\hline Current smokers & 2.6 & $1.0-6.4$ & 1.9 & $0.8-4.1$ \\
\hline \multicolumn{5}{|c|}{ Amount (cigarettes/day) } \\
\hline $\begin{array}{r}1-12 \\
13-24\end{array}$ & $\begin{array}{l}2.0 \\
1.9\end{array}$ & $\begin{array}{l}0.8-5.2 \\
0.7-4.9\end{array}$ & $\begin{array}{l}1.4 \\
1.7\end{array}$ & $\begin{array}{l}0.6-3.3 \\
0.7-3.8\end{array}$ \\
\hline$\geqslant 25$ & 1.7 & $0.7-4.3$ & $\begin{array}{l}1.7 \\
1.4\end{array}$ & $\begin{array}{l}0.7-3.8 \\
0.6-3.1\end{array}$ \\
\hline \multicolumn{4}{|l|}{ Duration (years) } & 0.49 \\
\hline $1-39$ & 1.1 & $0.4-2.8$ & 1.1 & $0.5-2.5$ \\
\hline $40-49$ & 2.3 & $0.8-6.1$ & $\begin{array}{l}1.1 \\
1.0\end{array}$ & $0.4-2.7$ \\
\hline$\geqslant 50$ & 2.7 & $1.0-6.8$ & 2.3 & $1.0-5.0$ \\
\hline \multicolumn{5}{|l|}{ Pack years } \\
\hline $1-24$ & 1.5 & $0.6-3.9$ & 1.3 & $0.5-2.9$ \\
\hline $25-54$ & 2.7 & $1.0-6.8$ & 1.9 & $0.8-4.3$ \\
\hline$\geqslant 55$ & 1.6 & $0.6-4.1$ & 1.4 & $0.6-3.1$ \\
\hline \multirow{2}{*}{\multicolumn{5}{|c|}{$\begin{array}{l}\mathrm{p} \text { Value for trend } \\
\text { Type of tobacco }\end{array}$}} \\
\hline & & & & \\
\hline $\begin{array}{l}\text { Blond } \\
\text { Black }\end{array}$ & $\begin{array}{l}1.6 \\
2.0\end{array}$ & $0.6-4.1$ & 1.0 & $0.4-2.4$ \\
\hline \multicolumn{5}{|l|}{ Hand-rolling } \\
\hline Manufactured & 1.2 & $0.4-3.5$ & 1.0 & $0.4-2.6$ \\
\hline Hand-rolled & 2.1 & $0.9-4.9$ & 1.6 & $0.8-3.4$ \\
\hline \multicolumn{5}{|l|}{ Filter use } \\
\hline Filter & 1.3 & $0.5-3.7$ & 1.0 & $0.4-2.6$ \\
\hline Non-filter & 2.1 & $0.9-4.9$ & 1.7 & $0.8-3.5$ \\
\hline
\end{tabular}

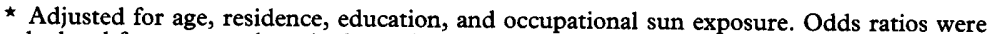
calculated for ever-smokers (unless otherwise indicated) using never-smokers as the referent

group.

$\mathrm{CI}=$ confidence interval

$\mathrm{NA}=$ not applicable.
Table 5 shows the odds ratios of nonmelanoma skin cancer according to histological type. Current smokers showed an increased risk of $2.6(95 \% \mathrm{CI}=1.0$ to 6.4$)$ for squamous cell cancer and 1.9 (non-significant) for basal cell cancer. Number of years of smoking had a stronger association with squamous cell carcinoma than with basal cell type. All remaining smoking variables (pack-years and use of handrolled and non-filter cigarettes) showed stronger associations with squamous cell carcinoma.

Exposure to sun in an occupational setting was associated with an increased risk of nonmelanoma skin cancer $(\mathrm{OR}=3.8,95 \% \mathrm{CI}=$ 1.8 to 6.5 ). Total alcohol consumption was not associated with an increase in risk (results not shown). The only foods that showed protective effects were milk and fresh fruits (ORs $=0.5$ and 0.6 , respectively, for the highest tertiles).

Table 6 shows effects of smoking duration on risk (for all histological types combined), stratified by occupational sun exposure. The results follow a multiplicative effect and no evidence of an interaction between tobacco smoking and sun exposure is apparent. The same analysis was performed separately for each histological type, and similar ORs were obtained (results not shown).

\section{Discussion}

Our results suggest an increase in the risk of skin cancer associated with tobacco smoking, more evident with longer smoking duration. In contrast with the study of Karagas et $a l l^{5}$ we found an association between smoking and an increased risk of basal cell carcinoma. Recently Frances et al reported that tobacco smoking could be a cofactor for basal cell carcinoma of the skin. ${ }^{8}$

Tobacco smoking has been documented as the main determinant of cancer of the lung, larynx, bladder, lip, oral cavity, pharynx, pancreas, esophagus, and kidney. ${ }^{9,10}$ Tobacco smoking may also be associated with an increased risk of cancer of the cervix uteri, ${ }^{11,12}$ vagina, vulva, penis, ${ }^{13}$ and stomach, ${ }^{14-17}$ as well as with leukemia, ${ }^{18,19}$ and anorectal squamous or cloacogenic carcinoma. ${ }^{13}$

Recently, the effect of smoking on skin aging has been established. Tobacco use and solar radiation represent two risk factors for the premature aging process, with a cumulative effect when both are present. ${ }^{20}$

The putative effect of tobacco smoking on the risk of non-melanoma skin cancer could be produced by carcinogenic substances carried through the blood, or by the direct contact of cigarette smoke on the skin. In support of the latter possibility, experimental studies have compared condensates of sidestream smoke (smoke generated during inter-puff intervals) (SS) and mainstream smoke (smoke inhaled by the smoker) (MS) by means of a skin tumorigenicity assay using female NMRI mice. The SS-treated animals developed two to six times more skin tumours than MS-treated mice. The overall carcinogenic effect of SS was much greater than that of $\mathrm{MS}(\mathrm{p}<0.001) .^{21}$ The sumption of 25 or more cigarettes per day and 25-54 pack-years were associated with significantly increased risks of 2.2 and 2.3 , respectively. 
concentrations of tobacco-specific nitrosamines (TSNA) are 10-50 times higher in SS than in MS. ${ }^{22}$

We have considered the possibility of selection bias in our study. Because the study was designed using controls treated in the same hospital during the same time period, the base population appears to be rather homogeneous. Moreover, the fact that $80 \%$ of the controls also had cancer provides further support that selection of controls was unbiased. Indeed, as tobacco smoking is considered to be more prevalent among cancer controls, ${ }^{23-25}$ an underestimate of the effect of tobacco smoking could be more likely than an overestimate.

We have also considered the possibility of biased referral leading to the inclusion of patients with advanced skin tumours. Six patients with large lesions were excluded and no patients in hospital were eligible for this study. Furthermore, the Cancer Institute has a referral pattern by which only patients with low incomes (less than US $\$ 350$ per month) are treated. This referral pattern is shared by other general state hospitals, which treat only patients of low incomes. Furthermore, because hospitals from outside Montevideo are lacking in dermatologists and plastic surgeons, all skin tumours are referred to state hospitals in Montevideo. All such hospitals in Montevideo are well suited for the treatment of nonmelanoma skin cancer, because they have dermatological outpatient clinics. Differential referral to the Cancer Institute is possible but unlikely. According to information submitted by the National Cancer Registry, the proportion of non-melanoma skin cancer among all cancers was roughly similar in the Hospital Pasteur (one of the major general state hospitals in Montevideo) and the Cancer Institute $(8.0 \%$ and $7.8 \%$, respectively).

The possibility of recall bias is unlikely because the association studied has not been suspected nor publicised. Moreover, as most of the controls had cancer, presumably they were as prone as the patients to link their illness with tobacco smoking.

Because the interviews were conducted routinely for all patients consulting at the Institute, the interviewers were blinded to the designs of any studies that used the recorded information.

We were able to control for possible confounding by occupational sun exposure but it was impossible to analyse confounding by recreational sun exposure, because this variable was not included in the questionnaire. Nevertheless, in models including terms for occupational sun exposure, the adjusted OR for smoking variables remained essentially unchanged. External validation for this association can be found in the studies of Aubry et $a l^{4}$ and Karagas et al. ${ }^{5}$ These studies fully controlled the effect of tobacco smoking for possible confounding variables related to skin colour and recreational sun exposure.

In conclusion, the present study supports an association between tobacco smoking and nonmelanoma skin cancer. Whether this association is causal remains an open question, and further studies should be performed.

1 Fraser MC, Hartge P, Tucker MA. Melanoma and nonmelanoma skin cancer : epidemiology and risk factors. Sem Oncol Nurs 1991; 7: 2-12.

2 Kricker A, Armstrong BK, English DR, Heenan, PJ. Pigmentary and cutaneous risk factors for non-melanocytic skin cancer-a case-control study. Int $\mathcal{f}$ Cancer $1991 ; 48: 650-62$.

3 Scotto J, Fraumeni JF Jr. Skin (other than melanoma). In: Schottenfeld D, Fraumeni JF Jr, eds. Cancer epidemiology and prevention. Philadelphia, Pennsylvania: WB 1982: 996-1011.

4 Aubry F, MacGibbon B. Risk factors of squamous cell carcinoma of the skin. A case-control study of the Montreal Region. Cancer 1985; 55 : 907-911.

5 Karagas MR, Stukel TA, Greenberg ER, Barn JA, Mott LA, Stern RS. Risk of subsequent basal cell carcinoma and squamous cell carcinoma of the skin among pacients with prior skin cancer. $\mathcal{F} A M A 1992 ; 267: 3305-10$.

6 Breslow NE, Day NE. Statistical methods in cancer research. Vol. I: The analysis of case-control studies. Lyon: International Agency for Research on Cancer, 1980.

7 Baker JA, Nelder RJ. The GLIM system. Release 3.77. Oxford: Numerical Algorithms Group, 1985.

8 Frances C, Chosidow O, Grob JJ. Quoi de neuf en dermatologie clinique? Nouv Dermatol 1993; 12: 332-3.

International Agency for Research on Cancer. Tobacco smoking. Monographs on the evaluation of the carcinogenic rmoking. Monographs on the evaluation of the carcinogenic risk of chemicals to humans, Vol. 38. Lyo
Agency for Research on Cancer, 1986.

10 US Department of Health and Human Services. The health consequences of smoking: cancer. A report of the Surgeon General, 1982. Bethesda, Maryland: Public Health Service, Office on Smoking and Health, 1982 (DHHS Publication No (PHS) 82-50179.)

11 Wilkenstein W. Smoking and cancer of the uterine cervix: hypothesis. Am F Epidemiol 1977; 106: 257-9.

12 Brinton LA, Schairer C, Haenszel W, et al. Cigarette smoking and invasive cervical cancer. $\mathscr{f} A M A 1986 ; 255$ 3265-9.

13 Daling J, Sherman KJ, Hislop TG, et al. Cigarette smoking and the risk of anogenital cancer. Am $\mathcal{F}$ Epidemiol 1992 ; and the risk $180-9$.

14 De Stefani E, Correa P, Fierro L, Carzoglio J, DeneoPellegrini H, Zavala D. Alcohol drinking and tobacco smoking in gastric cancer. A case-control study. Rev Epidemiol Sante Publique 1990; 38: 297-307.

15 Forman D. The etiology of gastric cancer. In: O'Neill IK Chen J, Bartsch $\mathrm{H}$, eds. Relevance to human cancer of $\mathrm{N}$ nitroso compounds, tobacco smoke and mycotoxins. Lyon: International Agency for Research on Cancer, 1991.

16 Hoey J, Montvernay C, Lambert R. Wine and tobacco: Risk factors for gastric cancer in France. Am $\mathcal{F}$ Epidemio $1981 ; 113$ : 668-74.

17 Correa P, Fontham E, Williams Pickle L, Chen V, Lin Y, Haenszel W. Dietary determinants of gastric cancer in South Louisiana inhabitants. F Natl Cancer Inst 1985 ; 75: 645-54.

18 Brown LM, Gibson R, Blair A, et al. Smoking and risk of leukemia. Am f Epidemiol 1992; 135: 763-8.

19 Brownson RC, Chang JC, Davis JR. Cigarette smoking and risk of adult leukemia. Am $\mathcal{f}$ Epidemiol 1991; 134 938-41.

20 Frances C. Tabac et peau. Nouv Dermatol 1993; 12: 237-9. 1 Mohtashimpur E, Mohtashimpur M, German PG, Erns H, Norpoth K, Mohr U. Comparative carcinogenecity of cigarette mainstream and sidestream smoke condensates on the mouse skin. F Cancer Res Clin Oncol 1990; 116 $604-8$.

22 Hecht SS, Hoffmann D. Tobacco-specific nitrosamines: an important group of carcinogens in tobacco and tobacco smoke. Carcinogenesis 1988; 9: 875-84.

23 Linet MS, Brookmeyer R. Use of cancer controls in casecontrol studies. Am $\mathcal{F}$ Epidemiol 1987; 125: 1-11.

24 Wacholder S, McLaughlin JK, Silverman DT, Mandel JS Selection of controls in case-control studies. I. Principles. Am f Epidemiol 1992; 135: 1019-28.

25 Wacholder S, Silverman DT, McLaughlin JK, Mandel JK Selection of controls in case-control studies. II. Types of controls. Am ₹ Epidemiol 1992; 135: 1029-41. 